\title{
A Pragmatic Approach to Managing Enterprise IT Infrastructures in the Era of Consumerization and Individualization of IT
}

\author{
Mohammad Hossein Jarrahi ${ }^{1}$, University of North Carolina at Chapel Hill \\ Kevin Crowston, Syracuse University \\ Kateryna Bondar, International University of La Rioja \\ Bernhard Katzy ${ }^{\dagger}$, Formerly of the Center for Technology and Innovation Management
}

\begin{abstract}
Historically, organizations owned and controlled the information technologies (IT) their employees used: telephone, inter-office memos, mainframes and timesharing systems. Today, employees often want to use their own IT: not only personal smart phones and tablets, but also Twitter and Google Docs. This new trend can diversify and extend enterprise the IT infrastructure, but leaves organizations struggling with technology uses that they cannot control. With the emergence of new technological paradigms in consumer markets and organizations, the management of IT infrastructure requires a more pragmatic and holistic approach that goes beyond simple technological considerations. In this paper, we present a three-part framework-technology, people and practicethat helps managers understand and mitigate these tensions. Drawing on two empirical studies of European executives and consultants from multiple management consulting firms, the paper further outlines changes taking place along the three aspects of the framework. It concludes by discussing three distinct approaches to the management of organizational IT infrastructure (passive, reactive, and pragmatic), and by offering greater insight regarding a pragmatic approach.
\end{abstract}

Keywords: IT infrastructure, social media, IT consumerization, personal computing, BYOD, digital natives

\footnotetext{
${ }^{1}$ Corresponding author: Mohammad Hossein Jarrahi, 200 Manning Hall, Chapel Hill, NC 27599 Email: jarrahi@unc.edu

+ Deceased
} 


\section{INTRODUCTION}

Historically, organizations owned and controlled the IT that their employees used. However, recent studies suggest that employees, particularly younger employees, increasingly prefer to use personal IT that are neither supplied nor controlled by their organizations (e.g., Harris, Ives, \& Junglas, 2012; Niehaves, Köffer, \& Ortbach, 2012). This phenomenon is often referred to as "bring your own device" (BYOD), and much has been written on the challenges of managing personal technology, especially security concerns (e.g., Morrow, 2012; Romer, 2014). However, personal devices are just the tip of a technological iceberg that includes the use of personal communication technologies, social media, in particular, and personal information management enabled by cloud services such as Dropbox or Google Drive (Castro-Leon, 2014).

Whereas these devices and services are undoubtedly useful, their use poses challenges to IT management in organizations. Because of concerns about security and protection of proprietary information, many organizations restrict access to these technological platforms or forbid the use of social media and other public Internet services (Jarrahi \& Sawyer, 2015; Warmer, 2013). According to Gartner, 50\% of large organizations blocked such websites in 2010 (Gaudin, 2012). These concerns reflect the common challenges for the management of organizational IT infrastructures including the adoption of social media or BYOD that may blur the line between work and personal life.

\section{Understanding the Challenges of Personal IT}

With the influx of new technological platforms being used at work, managers demonstrate a natural temptation to focus on the technology. However, we increasingly realize that technology is not the only element that is undergoing changes. It is part of a larger puzzle with other complementary changes taking place simultaneously (Avgerou, 2000). Organizations cannot hope to hold one piece of this puzzle in place. For example, the ownership of social relationships and the ways work practices are carried out have also changed. Changing technological capabilities, as well as changes in people's attitudes and work practices have spurred these shifts.

To capture the multi-dimensional nature of these changes, we frame the enterprise IT infrastructure as a system encompassing technology, people and work practices (See Figure 1). This view holistically accounts for multiple dimensions of emerging tensions in organizations as a result of a shift in any of the three dimensions. It is a perspective that goes beyond viewing IT infrastructure as a collection of technologies by directing our attention to interdependencies among technologies, people, and their work practices (Tilson, Lyytinen, \& Sørensen, 2010). 


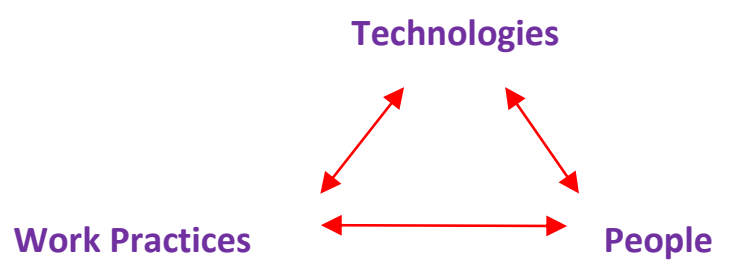

Figure1. The entwined relationships among technology, people and work practices

Technology: We know that technologies, in general, and information technologies, in particular, shape how people accomplish their work, and the diversity of information technologies plays a key role in all modern organizations (Davenport, 1995). In addition to being tools for work, they embody and can affect organizational norms, values, behaviors, and practices. Tensions can arise when new technologies pervade organizations and collide with legacy systems that embody a different organizing rationale, and are favored by people with contrasting worldviews and work practices (Abdinnour-Helm, Lengnick-Hall, \& Lengnick-Hall, 2003).

People: This dimension of the model encompasses how employees view their work, and, in a broader sense, factors such as culture and norms. The way people use technology for their work practices derives from their attitudes toward work and life. Some of the distinct impacts of IT on organizational practices are rooted in how people make sense of them, rather than being direct consequences of these technologies (Orlikowski, 2000).

Of particular interest, members of the generation now entering the workforce may hold a different perspective on technology and how work should be done (Oblinger \& Oblinger, 2005). These new workers are often labeled as the Millennials, Generation Y, Net Generation, or digital natives. These workers have grown up immersed in a digital environment in which technology has been integral to their workstyle and lifestyle (Salkowitz, 2008). The distinctive work style and engagement with digital IT of these tech-savvy workers thus differs from the work styles of preceding generations, who can be labelled as digital immigrants (Wang, Myers, \& Sundaram, 2013). The differing attitudes and behaviors can be a source of tension for the management of technological resources within and across organizations (McKeen, Smith, \& Jin, 2009).

Work Practices: Coordination within organizations is typically formally organized around a hierarchy and is executed through formal processes. However, a less visible dimension that is pivotal to the organization's performance is work practices (Brown \& Duguid, 2000). Work practice can be defined as recurrent and situated social actions performed by organizations members to accomplish their daily work (Orlikowski, 2000). Work practices are often not accurately reflected in either the organizational chart or its formal processes, but are how people actually accomplish their work. In new situations, work practices will involve workarounds and improvisation as people adapt how they work. 
In the remainder of this article, we use this framework as we report on our empirical studies of executives from different types of organizations, and consultants from multiple management consulting firms. From these studies, we uncover simultaneous sociotechnical changes happening in many organizations that help us identify potential issues and tensions regarding the management of IT infrastructures.

\section{RESEARCH METHODS}

This paper builds from two sets of field studies. The first study was conducted in Switzerland because of the country's high level of IT investment and because of the willingness of a group of swiss firms to participate in this research. Two of the authors interviewed Swiss managers from 18 knowledge-based companies across several sectors, including government, telecommunications, education, healthcare, banking, consultancy, and tourism. We conducted 24 interviews with senior executives (CEOs, CIOs and the HR managers) to incorporate three different perspectives (CEOs - company's strategy, vision for the future; $\mathrm{ClOs}$ - technological perspective; HR managers - employees' behavior, new leadership styles).

Before the interview, each respondent received and reviewed a document about the purpose of the study, procedures, and its benefits, together with a one-and-a-half-page provocative scenario reflecting the emerging issues in IT management and use within and across organizations. In the scenario, the main character, the $\mathrm{ClO}$ of a high-tech company, is going to a meeting with project managers to discuss the behavior of their newly hired employees: their tendency for a high level of collaboration on social media, the use of Internet for sharing experiences, and leverage of external connections to solicit help on projects. As he is going to the meeting, he is thinking about the issues related to IT management that his managers have pointed out to. For our interview, we asked the participants to reflect on the scenario and any other aspects of IT management relevant to their respective organizations. Respondents were only lightly guided by questions and were allowed to respond to the issue related to topics in the scenario, which served as a common starting point for analysis. Each interview lasted 60 to 90 minutes and was transcribed.

In the second study, we focused on management consulting firms. These firms are archetypal knowledge intensive environments and can be considered harbingers of possible futures. This work combined four forms of data collection: interviews, micro-studies of practice, and documents. However, the primary source of data for this research is the interviews with 58 consultants (informants) from multiple management consulting firms. Participants were identified through purposive sampling of our possible contacts. To provide a basis for comparison, they were selected based on the similarity of their work context, the comparability of the work roles they performed and their ability and willingness to provide key information. 
We pursued a broad range (maximum variation sample) of age, gender, and position level in the organization (managers vs. non-managers). The interviews elicited how these people share knowledge within and across boundaries and how social technologies and other types of IT support their work practices. In particular, the interview protocol included questions about: (1) the participants' professional background, (2) the nature and structure of work, (3) the roles of different ICTs including social technologies in work practices, and (4) the organizational context, norms and policies that define the participant's work practices. These interviews, on average, took 43 minutes, and were transcribed verbatim.

We also conducted five micro-studies of practice in order to better understand consultants' daily uses of social technologies in their work practices. We shadowed five participants and observed their work practices. These participants were identified based on their willingness to participate and on their knowledge-intensive work as management consultants. Observations focused on worker's knowledge sharing activities and their uses of social technologies in their work. These micros-studies took, on average, four hours and generated a wealth of field notes.

To supplement the interview data and micro-studies, we analyzed a variety of personal and organizational documents. During interviews, we asked for relevant documents such as the organization's social media policy or appraisal documentations (e.g., annual performance review documents). In total, we acquired ten documents, with the most relevant types to the research being "code of business ethics", "email policies" and "internal and external social media policies". Codes of business ethics defined acceptable work behavior, but could also specifically guidelines for technology practices.

Together, the two studies allowed an examination of technological changes in the workplace as well as changes in the attitudes and practices of both employees and managers. The first study centered on the organizations' policies and the attitudes of managers towards IT infrastructure, whereas the second study primarily focused on employees' perspectives in knowledge-intensive contexts as well as some policy-related issues. Even though the two studies did not embrace variations of organizational settings, we still believe that they generated a useful lens into meaningful commonalities among knowledge-intensive contexts, different aspects of IT infrastructures and respective sources of tensions.

\section{CHANGING NATURE OF TECHNOLOGIES, PEOPLE AND PRACTICES}

In line with some recent studies of IT uses in organizations, our empirical findings highlighted salient ongoing changes in the technology, work practices, and people dimensions of the studied organizations. These shifts resulted in challenges relative to the management of IT infrastructure in these organizations. 


\section{Technology Changes}

\section{Technology owned by individuals}

The first change is that information technology has become cheap and as a result accessible to a larger portion of society. Historically, information technology was expensive and so available only to wellendowed companies. A single production or management technology was the sole player in most organizational contexts. Because information and other types of resources were only available on site, work using them took place only during the working hours. Today, in contrast, technology is being decentralized and is no longer a matter of the firm's privilege, but a commodity that many can possess (Carr, 2003). Consistent with this insight, we found many of the participants had access to a diversity of technologies, from personal laptops and smartphones, to cloud services such as Dropbox, to social media including Twitter, Facebook or Linkedln, to "cool devices" such as new tablets. The ubiquity of technologies similarly pervaded the studied organizations in such a way that they were not dominated by a single IT, but instead, managed assemblages of diverse technologies.

What is more, with the emergence of new technological paradigms such as cloud computing, our participants can now leverage distributed technological capabilities that are increasingly independent of the company they work for. Many employees use their own personal information tools such as Linkedln, Twitter, and smartphones for both work-related and personal purposes, sometimes because these platforms were considered more effective than internal systems in supporting certain knowledge practices. A primary advantage of external social media over internal systems is extending the reach of workers' search and creating an inter-organizational information platform for locating experts. For example, LinkedIn supports expert locating practices though its communities and profile search. In particular, for workers in technical roles, Linkedln communities offer forum-like capabilities where a question can be brought to the attention of members of a large community who share interests in and expertise about the same topic. One informant notes: "LinkedIn has actually been very helpful, especially for commercial products, some of the collaboration software we use and my cycle management software we use have communities on Linkedln and it's been very useful to go there and post when we run into bugs and problems we post to the groups in Linkedln and get direct responses from people who are also having a problem or using a software and have to work around." Beyond finding solutions to immediate work problems, another contribution of public social networking platforms is a heightened awareness about a large number of social/professional contacts and colleagues (not necessarily from the same organization). The use of public social media can specifically result in more understanding about people who are adjacent to a knowledge workers' personal network. One informant indicates how awareness about professional contacts directly impacted his work: "For example, we were interested in pursuing business with the National Energy 
Resource labs, and in that particular case, I was able to leverage LinkedIn, and found some former coworkers of mine that are currently working there. This is an external person (he did not work for my current company); so somebody I'd worked with previously."

Work is therefore increasingly conducted using technologies over which organizations have little control, making the coordination and communication activities less dependent on the organization's sphere of influence. For the same reason, many consultants were hesitant to use the internal social network platform provided by their organizations; one participant notes: "If there's a message on Facebook, that's what I would care about. But I don't have the time for [the name of the internal social network system]; I'm like why should I use it when I have Facebook, when I have LinkedIn for my external and internal network."

\section{Technology consumerization}

When only corporations could afford sophisticated technologies, technology developers primarily targeted the corporate market. However, as technology has decreased in price, developers increasingly focus their attention on the much-larger consumer market. With increased consumerization, many new technologies are first experienced outside organizations and proliferate in consumer markets (Harris et al., 2012). Recent technological innovations, such as pervasive broadband Internet access and Web 2.0 technologies, have lowered the knowledge barriers to the use of new technology, such that more workers now encounter them first in their personal lives and then consider ways to integrate them in their work practices (Leclercq-Vandelannoitte, 2015b).

More specifically, digital natives have grown up with technology "right in their hands" before even joining any company (Howe \& Strauss, 2009). Indeed, in relation to the companies included in our research, we observed that many workers tended to own technologies that are more capable than those provided by their companies (e.g., a more powerful PC intended for gaming rather than word processing, or a personal smart phone). We observed that many employees are no longer satisfied with the technologies provided by the IT department given their experience as consumers with technologies seen as more powerful, more useful, and more fun than enterprise IT. As compelling alternatives to what had previously been a superior technological resource within the internal IT organization, ubiquitous consumer technology has given many employees the motivation to question the IT department's decisions, and pose questions such as "Why can't I do my work with what I already use at home?" (Shelton, 2013).

The contrast between consumer and organizational technology mirrors tensions between the use of legacy information systems versus emerging technologies. What often further fuels those tensions is the typical mentality of many IT managers, which is not always congruent with the dynamics of the consumer market (D'Arcy, 2011). A common IT management norm has been to focus on a deliberately 
planned lifecycle: acquiring software licenses for relevant hardware, implementing and then recouping the investment by supporting that hardware for a decade or more. This norm does not keep up with the quickly moving consumer technology market that constantly raises the expectation of IT users, particularly digital natives.

Our findings suggest that this common approach to technology management leads some younger workers to lose patience with the rate of change in the official IT environments. On the flip side, we recognize that technologies developed for consumers may lack critical features, such as manageability or conformity to security requirements. Some of the firms in our sample felt rightly concerned about having corporate information stored in a third-party system such as Google or Dropbox. Whereas IT consumerization is considered to positively contribute to employee performance by increasing satisfaction, flexibility and mobility (Harris et al., 2012; Niehaves et al., 2012), it may also lead to undetectable movement of sensitive information into personal devices and personal cloud storages, and consequently the inadvertent and risky co-mingling of enterprise and personal information (Winter, Berente, Howison, \& Butler, 2014).

\section{Constant connectivity and access to information resources}

The ease with which people can access information sources can be attributed to the infusion of communication and social technologies. These technologies have become more robust and ubiquitous. As an example, cellular networks are now more widespread, and Wi-Fi Internet connections are available in more places. One of the most significant technological changes in the organizations we studied had to do with a high penetration of mobile technologies among the workers. This echoes recent surveys suggesting that smart mobile phones are on course to replace traditional computers as the primary devices used to get online (e.g., McGrane, 2013). These technologies enable a broader range of communication and collaboration options. However, they can also create constant and inclusive connectivity and informal expectations obligating consultants to check their email on their smartphone even during non-work hours. The following interview excerpt reflects this informal assumption: "I'm hooked to my Blackberry...even though the company did not directly ask us to check the email on the move, but because they gave us this mobile phone we assume that there is an expectation..."

In tandem with the proliferation of mobile devices, an increasing use of cloud services, be it enterprise or individual, facilitates informant access across time and space. Thanks to cloud computing capabilities, workers can access information and computing resources wherever they like. Using personal cloud services (e.g., Google Drive or Dropbox), many workers can now expose and access information on their own personal cloud faster and more broadly than ever before. As noted, these uses may be invisible to the organization and pose challenges to the control of intellectual property 
and confidential information of the organization that might be inadvertently exposed through personal clouds (Costello \& Prohaska, 2013).

\section{Social Changes}

\section{The changing workforce}

Our findings highlight that the workforce within the studied firms is undergoing changes as a large portion of the population (Baby Boomers) heads into retirement, and is followed by members of younger generations. The difference in values and perspectives may be a source of tension and potential issues. When it comes to social practices, the new generation of workers has grown up in social environments that require fluid, flexible and agile social practices. Digital natives have also developed certain skills and norms of technologies that are different from those of the previous generations. In particular, previous research demonstrates that digitally natives have different perceptions of social ties, job security, privacy, the distinction between personal and professional life, the use of technology for socializing, and informal knowledge sharing (e.g., Carter, Thatcher, Applefield, \& Mcalpine, 2011; Leclercq-Vandelannoitte, 2015a; Tilvawala, Sundaram, \& Myers, 2013; Vodanovich, Sundaram, \& Myers, 2010).

Digital natives often have a distinctive perspective on the use of personal devices/applications in and for work. Digital natives tend to be among the first workers to adopt new IT, since the age at which they started to use social media, smart cell phones and similar technologies seems to have had profound implications for the way they learn and work in technology-mediated environments (Salkowitz, 2008). It is evident that they are more supportive of BYOD trends, as they see the potential benefits based on their personal experience and want to exploit these technologies in the same way in the workplace (Weeger et al., 2015).

Digital natives are also more likely to use ubiquitous information systems such as Facebook, YouTube, and Twitter for both personal and professional purposes (Vodanovich et al., 2010).

Our empirical observations suggest that computing devices are inseparable elements of digital natives' social interactions in their daily life and work. The following excerpt demonstrates the salient role of digital technologies in the social interactions of younger consultants: "We live in that generation; I grew up in the instant messenger world, so sometimes even if the person is next to you, you might IM them ... even if the person sits a row behind you, it's sometimes quicker to just type out hey do you have this or something, rather than getting up every time you have a question."

In contrast, legacy systems were developed to address the communication needs and norms as well as the work style of those working when they were developed. Older research participants tend to consider the use of IT as pertaining only to business purposes, and may view the informal communication enabled by these tools as a "productivity killer." In contrast, younger participants 
continue to insist on bringing personal consumer tools to use for their work, and will see "the rejection of the latest generation technology as an affront to their personal wellbeing" (Fister, 2010).

Many managers may also see knowledge sharing across organizational boundaries as a risky activity. In contrast, many digital natives hold a different perspective as they have been accustomed to using social technologies for sharing knowledge with their personal networks since their teen years. This form of knowledge sharing, taking place independent of formal ties and rules, worried some managers from the companies we studied, typically those from older generations. These channels were viewed as entailing the risk of the leakage of proprietary information, intellectual property, and the conflation of personal life and work.

\section{Relationships owned by individuals}

Digital natives tends to view the world as interconnected, since they increasingly identify themselves as members of a social network (Tapscott, 2009). What may primarily bind these people together is social capital gleaned from social networks rather than the bureaucratic forces of institutions (Howe \& Strauss, 2009). Indeed, they may be more loyal to their interpersonal social network than to an organization. Particularly for our digital native participants, the social aspects of work are instrumental in shaping one's satisfactions. As a result, they expect to be allowed to stay in touch, communicate, and collaborate with their social contacts. Even though we observed variation in using social media among digital natives due to such factors as different personality types, we still found the use of these technologies pronounced in their work practices. A young consultant highlights this common use of public social media for work-related purposes: "Unless what I'm working on is confidential, or too private, I have no hesitation in just tweeting out and asking 'hey, has anybody heard this? I'm always shocked, because sometimes a person that I've never talked to before will respond, and other times, 4 or 5 people will respond from my network."

Many of these social interactions cross organizational boundaries. However, this does not mean that the contacts are entirely personal. In line with many other empirical observations (e.g., Nohria, 1998), our findings reveal that the assemblage of these social ties forms broader interpersonal, and interorganizational networks that underlie most knowledge practices in contemporary workplaces. Informal networks that cut across organizational boundaries are by no means new phenomena, but the advent of social technologies has allowed individuals to form and maintain larger-scale social networks. So, the social interactions that underpin much of organizational knowledge sharing and communication practices have become less dependent on an organizational sphere of influence. As the notion of triad implies, the use and purposes of new social technologies is congruent with the network-centric work practices of digital natives. For example, a defining element of social media is that these technologies build on and contribute to social networks (Jarrahi \& Sawyer, 2015). 


\section{Practice Changes}

\section{Fading division between personal and professional life}

Research suggests that the prevalence of new technologies has changed employees' attitudes toward work and blurred the division between private and professional lives (Mazmanian, Orlikowski, \& Yates, 2013). In the past, personal life was associated with the physical home, and work life existed primarily at the workplace, that is, there were clear spatial boundaries between work and personal life (Orlikowski \& Barley, 2001). Work would typically end at the end of the working day, enforcing as well temporal boundaries between work and personal life.

Today, the extensive use of (personal) information and communication technologies and the rise of a wide variety of mobile technologies have blurred temporal and spatial boundaries in the work of many of our participants, making the distinction between personal and professional personas less relevant. Providing workers flexible timings and locations for work, these technologies allow workers and managers alike to permeate what were previously fairly clear boundaries between work and life (Hyman \& Summers, 2004; Sadler, Robertson, Kan, \& Hagen, 2006) and contribute to an 'always available' work culture. Mobile devices and applications now allow work-related communications to continue beyond corporate offices and work hours. Testifying to the pervasive informal expectation about checking emails we noted earlier, a junior consultant states: "If the company provides you with a [smart] phone, there's a kind of unsaid expectation that you're expected to check e-mail at any time of the day... I feel that it's a part of my responsibility that I should be on top of everything. So you could say that it's a mix of personal and work related expectations."

\section{Change in the locus of work}

Organizations are, in essence, defined by coordination mechanisms and these mechanisms are strongly affiliated with the communication technologies available (Malone \& Laubacher, 1998). Constant connectivity and easier access to information and communication resources endow employees with the freedom to coordinate work while being less tied to any one physical location, be it a corporate office or a home office (Erickson, Jarrahi, Thomson, \& Sawyer, 2014). Coupled with remarkable developments in mobile and collaborative technologies, changes in work practices have rendered mobile work a common trend in all the consulting firms in our sample, giving rise to novel organizing concepts such as "nomadic workplaces." In nomadic workplaces, employees have a different relationship to time, workplace, and colleagues. Nomadic work style in fact is fast becoming the norm for most knowledge intensive work (Davis, 2002). Most knowledge workers in America spend less than a third of their working time in traditional corporate offices, about a third in their home offices, and the rest working from other places such as cafés or public libraries (Kluth, 2008). 
A large number of the knowledge professionals we interviewed do not depend on place- or sitespecific resources or functions, and are not constrained to specific locations or times. Instead, most of their work practice can be carried out by working away from centralized organizations, in a distributed or mobile modality. With the rise of technological capabilities such as smartphones and short range $\mathrm{Wi}-\mathrm{Fi}$, mobility pervades the consulting firms we studied. It provides consultants with the freedom to work and collaborate with colleagues without being tied to any one physical place, be it a corporate office or a home office. This shift enables a very flexible work style, in which consultants are empowered to choose where, when, and how they prefer to work.

The pervasiveness of mobile technologies also lets consultants, particularly the younger ones, untie themselves from organizational infrastructure and more easily check social media websites such as Facebook. Several informants state that even though public social media are not blocked at work, they use their smartphones to access them. One informant noted: "You can access Facebook through our work laptop, so it's not blocked. But I use it on my personal phone anyway, so it wouldn't be an issue - because it's not [the company's] phone, it's my phone."

Virtual teams and workers represent further changes in the locus of work in consulting firms. Organizational members now form virtual teams to overcome time and space boundaries, collaborating with colleagues at a distance and in different time zones. These virtual collaborations run contrary to conventional notions of workplace and organizational units. We found the following situation increasingly common in the consulting firms included in our study: "For the current project; half of the team is out of Chicago, the other half is in Virginia, and I'm the only one from New York. So whenever we have to discuss something we either jump on a call or an online meeting, so you don't necessarily have to be in the same office at the same location."

These changes can be sources of tension in many organizations, as they undercut more traditional organizing paradigms that require employees to work in certain locations and at certain times. Shifts in work practices and mediating IT also impact perceptions of the workplace. Many employees now make their own decisions where they want to work. Organizational members are more likely to work on the move and outside of conventional workplaces. As a result, we found many of our participants have become less bound to physical location, and their attitude towards needing a stable workplace has undergone a substantial transformation. These trends are accelerating as more digitally savvy young workers enter the workforce. These sociotechnical changes influence the way work practices are conducted and the way organizations are structured. Novel organizational practices supported by the growing numbers and different types of digital technologies, coupled with the increasing presence of virtual work practices, highlight the fact that many 'hard copy' institutions gradually go virtual, and resources can be accessed from anywhere (Zammuto, Griffith, Majchrzak, Dougherty, \& Faraj, 2007). 


\section{Tensions Arising from Continuous Changes}

As the above changes emerge within and across organizations, their interplay may lead to various tensions. These tensions unfold because interdependences among technology, people and work practices are being constantly reconfigured. With changes in one dimension, the other legs of the triad must also evolve. For example, the emergence of a popular new technology in the consumer market or social contexts outside the organization may cause strains as employees engage with new technologies until they suitably transform their work practices and develop new conventions.

It is important to note that particular technologies or work practices and routines may be advocated by different groups of organizational members. For example, consistent with extant research (e.g., Vodanovich et al., 2010), we found that the older generation of consultants (digital immigrants) were typically more comfortable with the more conventional perspectives on how work should be done and technology should come into play, while the attitudes and behaviors of the new generation of knowledge workers was more likely to challenge the traditional convention of technology use and mentality of workplace as fixed and stable. Digital immigrants tend to be more comfortable with topdown information environments wherein the source and authority of expertise is evident, well-known and often tied to command-and-control hierarchy as the primary organizing principle of traditional management (what Gary Hamel (2009) calls Management 1.0).

Digital natives, on the other hand, are likely to prefer decentralized and bottom-up networks. Their use of collaborative technologies such as social media reflects a new mentality of workplace that advocates a more egalitarian, bottom-up, self-managed, transparent information space (what Hagel and Brown (2011) call pull platforms). As Salkowitz (2008) suggests, the diverging practices and organizing paradigms necessary to motivate digital natives constantly challenge the sociotechnical balance espoused by many digital immigrants.

With respect to convention and norms of technology use, digital natives may prefer to bring their own ubiquitous technologies and applications into the organization (Tilvawala et al., 2013). Digital natives constantly seek to integrate technology in ways that increase their flexibility, and they are more likely to experiment with ubiquitous information systems at work (Finn \& Donovan, 2013). These younger workers are not just "passive users" of enterprise IT infrastructure; rather, they are active participants in a new digital media culture (Vodanovich et al., 2010), propelling modern organizational IT services to become more free form, informal, and participatory (Boulton, 2007). For example, this young workforce may be less compliant of traditional IT management policies and therefore less inclined to draw firm boundaries between enterprise and personal technologies (Leclercq-Vandelannoitte, 2015a). Many of them rely heavily on a multitude of consumer technologies in their personal lives and expect to have access to state-of art tools for collaboration and execution for work as well (Finn \& 
Donovan, 2013). A recent poll shows that one-third of Millennials are willing to forego a higher salary to work at a workplace that does not restrict access to technology, and 56 percent won't accept a job which prohibits access to social media at work (Warmer, 2013).

Our empirical findings demonstrate that most of the organizations we studied are in a transition, and many executives are presently grappling with the tensions arising from the evolution from the more conventional ways technologies, workforce, and work practices are interconnected to an emerging state. The following table highlights key aspects of this transition along the three dimensions of the triad.

Table1. Changes along the three dimensions

\begin{tabular}{|c|c|c|}
\hline $\begin{array}{l}\text { Information } \\
\text { Technologies }\end{array}$ & $\begin{array}{l}\text { - Proprietary } \\
\text { - Owned by the organization } \\
\text { - Centralized } \\
\text { - Designed for business purposes }\end{array}$ & $\begin{array}{l}\text { - Cheap } \\
\text { - Owned by individuals } \\
\text { - Ubiquitous } \\
\text { - Consumerized }\end{array}$ \\
\hline People & $\begin{array}{l}\text { - More bound to the organization } \\
\text { - Information sharing within } \\
\text { boundaries } \\
\text { - Separation between work and } \\
\text { personal life }\end{array}$ & $\begin{array}{l}\text { - Less bound to the organization } \\
\text { - Information sharing across boundaries; } \\
\text { Blurred line between work and } \\
\text { personal life } \\
\text { - Technophile }\end{array}$ \\
\hline $\begin{array}{l}\text { Work } \\
\text { Practices }\end{array}$ & $\begin{array}{l}\text { - Hierarchical coordination } \\
\text { - Tied to physical spaces } \\
\text { - Stable }\end{array}$ & $\begin{array}{l}\text { - Self-coordination } \\
\text { - Virtual and distributed work } \\
\text { - Nomadic } \\
\text { - Multi-tasking } \\
\text { - Fluid }\end{array}$ \\
\hline
\end{tabular}

\section{IMPLICATIONS FOR MANAGERS}

The ongoing sociotechnical changes noted earlier suggest that part of the IT managers' duty is to understand this transition and ensure that the interests of both organizations and their employees are served.

\section{What Must Managers Do to Pragmatically Address the Tensions?}

Our empirical findings suggest three distinct approaches that managers typically take in the face of these tensions: passive, reactive, and pragmatic. The following table outlines the major differences among these approaches. The continuum also provides a representation of the degree and direction of intervention each approach adopts.

\section{0}

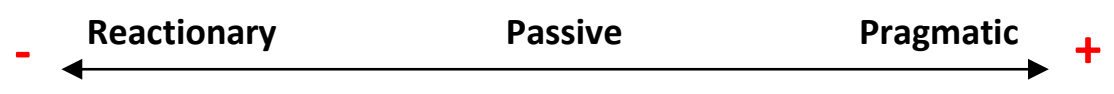

Figure2. The degree and direction of interventions 
Table2. Three approaches to management of IT infrastructure

\begin{tabular}{|l|l|l|l|l|}
\hline Approach & \multicolumn{1}{|c|}{ Objectives } & \multicolumn{1}{|c|}{ Focus } & Mechanisms & \multicolumn{1}{|c|}{$\begin{array}{c}\text { Role of } \\
\text { managers }\end{array}$} \\
\hline Passive & $\begin{array}{l}\text { Avoiding } \\
\text { intervention }\end{array}$ & None & Wait and see & Hands-off \\
\hline Reactive & $\begin{array}{l}\text { Preserving old } \\
\text { status quo }\end{array}$ & $\begin{array}{l}\text { One dimension of the triad (often } \\
\text { technology) }\end{array}$ & Control & Controller \\
\hline Pragmatic & $\begin{array}{l}\text { Facilitating } \\
\text { transition }\end{array}$ & Holistic: All dimensions & Collaboration & Guide \\
\hline
\end{tabular}

\section{Passive Approach}

Faced with these changes and associated tensions, some managers may throw their hands in the air, adopting a risk-aversive approach, often referred to as a "wait and see" strategy. These managers do not deal with tensions, and try not to get directly involved. They do not take any action until it is absolutely necessary. Our data reveal that this approach may arise from a lack of confidence on the part of managers about the best course of action. As one manager admitted: "I think we are a follower in technology... We don't even know how to decide between iPhone, Blackberry or HTC. We are not proactive looking for different ways of [constructing] the IT environment. We are quite limited in that." Past studies make clear that because of the volatile nature of the business and IT environment within which an organization operates, competition cannot be accommodated through a passive approach (e.g., Newkirk \& Lederer, 2006). For example, competitors can easily attract employees who are not satisfied with how their current organization handles their demands, or competitors in the same industry could gain an edge by taking advantage of their employees' digitally-enabled social networks, leaving more passive companies behind.

\section{Reactionary Approach}

In the reactionary approach, the instinctive response to the challenges is preserving the status quo. These managers react to changes by taking countermeasures, in the form of blocking access to undesired services such as Twitter or Facebook, or imposing strict technology-use policies. The approach is top-down and often aimed at reinforcing existing acceptable work practices and technology use behavior. The following excerpt from an interview with a human resource (HR) manager of a large bank reflects this common view among many financial institutions (Kaplan, 2012): "Because you are a bank, your security standards are strictly regulated, and that's why our employees cannot use social networks here, they can't share data or knowledge easily outside the company." In dealing with tensions, these managers focus on regulating employee's behaviors through rules and policy. This reactive approach may result from distrust regarding the use of public social platforms. As 
one manager noted: "These people talk about projects in public areas in Facebook and we don't want that, so let's close down the access."

The top-down approach adopted by these managers often depends on control and surveillance. For example, some enterprises and government agencies recently began to ask job applicants for logins for their public social networking profile to allow the prospective employer to screen the contents (Valdes \& Mcfarland, 2012). It is understandable that this strategy remains popular in highly regulated industries/sectors (e.g., financial services, healthcare and government) where security and privacy of information are of paramount concern (Finn \& Donovan, 2013).

This approach has alienated many applicants, who considered it an egregious privacy violation. In many cases, such reactive approaches also prove counterproductive. Although they may show results in the short term, they often produce negative consequences such as the long-term demotivation of the workforce. Intimidated, unhappy employees who are subject to external forces may feel suffocated and are more likely to leave an organization, possibly for a competitor (Fleming \& Marx, 2006).

\section{Pragmatic Approach}

Finally, we observed that some managers have begun to take a more active approach to handling the tensions spurred by continuous changes, paying attention to the inseparable relationships among technology, people, and their work practices. In taking this approach, managers recognize that policies affecting one dimension will result in changes in the other dimensions. Seeing organizational change as organic and bottom-up, this approach is both proactive and pragmatic, and focuses on what managers and organizations can realistically achieve.

Based on our analysis of the evolving technology, and the use by people in their work practice, we suggest that for managers pursuing a pragmatic approach to managing changes in IT infrastructures, the following seven principles can serve as general guidelines. These may help managers influence shifts in the elements of the model towards more productive operations.

1) Recognizing the inter-organizational nature of IT infrastructures: The IT infrastructure interacts with the organization's environment. This inter-organizational sphere cannot be subsumed under the control of any one organization. In our dataset, companies with pragmatic strategies have recognized the trans-organizational nature of the infrastructure and its characteristics, such as the eroding line between personal and professional lives. Rather than prohibiting it completely, this pragmatic approach defines how their employees may act in this environment. For instance, one firm's social media guidelines reads: "Conversations on the social web are public by default, can reach millions in an instant and leave a lasting record forever. There is no separation for others between your personal and your business profiles within social media. You must be aware of that and the effect this can have 
on your personal and professional reputation. Always maintain a tone of respect and professionalism. Never use profanity or demeaning language."

Instead of ignoring or trying to block social media, this specific policy aspires to guide usage in productive directions. Likewise, we found that several firms developed HR and marketing strategies for leveraging public social media and actively using them for recruiting new talents, branding, and interacting with customers.

2) Guiding the transition to a productive state: Managers adopting an effective pragmatic approach seem to have taken clear lessons from past experiences with similar technologies that reveal the same types of concerns. Email found its way in to enterprises when it was initially used by students and on consumer systems such as AOL. We know many managers greeted these technologies with similar resistance, viewing informal communication channels as a distraction (Efimova \& Grudin, 2008). Over time, however, the use of email shifted the technological infrastructure by providing value to organizational communication and sharing practices. Organizations therefore began to identify the value, weaving policies around the use of email, a technology now considered an inseparable component of organizational communication. More recently, instant messaging has followed a similar trajectory, starting with consumer-oriented systems such as AIM and moving in to the corporation. These historical lessons convinced some managers that instead of leading the infrastructure through command and control, they should participate in the transition as guides who facilitate change and assure the welfare of both the organization and its employees. No matter which type of company these managers lead, they seek to get involved in the new ways of work. This management style requires managers to "guide, nudge and persuade" rather than to command (Malhotra, Morris, \& Hinings, 2006p. 175). Through this proactive approach, managers can push the strategy by communicating organizational expectations, using technologies themselves, and setting examples for their employees. For instance, among the firms we studied, we came across an organization whose $\mathrm{ClO}$ used blogging to address employees' frustrations with the existing IT infrastructure. In this manner, while clarifying the IT strategy, he also served as a guide, generating useful examples that proved that the informal nature of blog postings and resulting interactions such as commenting activities can create and foster informal linkages among different groups of knowledge workers.

3) Recognizing the bottom-up transition: The triad suggests that when one element is changed, effects reverberate throughout the IT infrastructure. Technologies introduced and reinforced in a topdown manner can easily disappear in IT infrastructures if they are incompatible with the rest of the infrastructure, such as work practices, employees' values, and individual preferences. Mangers adopting a pragmatic approach are well aware that the adoption of social technologies, particularly those deployed internally and behind firewalls cannot be imposed by managerial fiat. The way new 
technologies have traditionally been deployed in organizations has built on mechanisms such as small controlled pilot rollout (Swanson \& Ramiller, 2004). The nature of social technologies is at odds with control, so these mechanisms may mitigate their benefits. In contrast, successful deployments often let social technologies grow organically (McAfee, 2009). Via a bottom-up and organic approach, workers take the initiative themselves and embrace user-driven IT for work-related purposes (Györy, Cleven, Uebernickel, \& Brenner, 2012); such technology use might then be diffused throughout the organization, and get assimilated into practices and policies of the organization (LeclercqVandelannoitte, 2015b).

Our findings also document that knowledge workers make extensive use of the diversity of tools at their disposal. Organizations may benefit from giving their employees the liberty to explore these tools to reach out to different social contacts and for alternate knowledge sharing goals. In particular, in successful instances of internally-deployed social tools, espoused by organizations in our sample, the tool was effectively integrated into this broader portfolio of tools. Our findings further reveal that a few firms require their employees to use certain social tools. If employees are required to follow such rules, they may create a façade around these systems rather than substantively engaging with the system. This type of use may be incapable of producing value at the personal and organizational levels. One consultant characterizes this adoption behavior: "In my role, I don't have to use [internal enterprise social networking technology] very often. I don't need to do that type of thing, so I haven't had to use it for anything other than keeping my own information updated, which is a requirement for us to do. Every 6 months we have to at least have revisited our resume and, and visited the skills at all the places where we put in all of our skills that we have, so that people can search on it if they need to."

4) Taking a practical approach: One important factor distinguishing the third approach (pragmatic) is the realization that the organization may no longer own many of the technological platforms in use by their employees. Therefore, some mangers recognized that managing technologies and their use in traditional ways was not always possible. Blocking public technological platforms is neither productive nor feasible. Many organizational members currently have access to smartphones separate from their organizational technological infrastructure (French, Guo, \& Shim, 2014). As a result, even if websites such as Facebook and Twitter are blocked on a corporate network, employees can easily access them on their smart phones, leaving the company with even less control of security and confidentiality. As well, several research participants recognized that too much control hindered technology-enabled social collaboration; therefore, they chose to cede some managerial control to help the IT infrastructure evolve. One manager echoes this pragmatic perspective: "We have decided not to adopt a restrictive policy or practice assuming that the use of social networks and online 
collaboration is something that cannot really be stopped, and putting any constraints on those things usually doesn't stop it. The more you make it forbidden the more interest you get."

New technological trends have clear implications for the way IT infrastructures for work can be realistically managed and IT policies are devised. For example, BYOD is built on devices that the organizations does not own, so security policies cannot be enforced in the same way as for technologies owned and controlled by the organization (Miller, Voas, \& Hurlburt, 2012). We found that mechanisms such as personal authority or positional power are less useful in guiding the transition. Instead, managers need to formulate policies that encourage responsible use of social technologies. Acceptable-use policies must focus on what organizations can control and benefit from. Rather than being overly restrictive and prescriptive, these policies can highlight potential risks and safeguard organizational interest against threats such as leakage of confidential information. Our findings suggest that organizations with pragmatic strategies have clear definitions and guidelines regarding using personal devices; sharing confidential information, including the company's financial information; intellectual property; non-disclosed business plans; and information about employees, customers, or product announcements.

Both employers and employees have to be mindful of potential security and privacy risks, while employees are allowed to use their own technologies for both professional and personal lives. Employees have to be aware of and agree to a technology use-policy, and their use of personal devices/application has to meet a defined set of specifications, clearly laid out by the organization (Harris et al., 2012). For example, both employees and employers need to understand who owns the information on a personal device used for work, who will be held to account in the event of loss or theft of hardware, and what happens to organization-related data when the employee resigns. As a result, such policies can be thought of as risk mitigating measures for both the employer and employee.

A realistic approach also calls for top management's recognition of the strategic role of IT infrastructure in overall performance of the organization, and its appreciation of the importance of ubiquitous and individualized information systems in enabling user-driven IT innovations (LeclercqVandelannoitte, 2015b). As the implications of these technological changes go beyond the boundaries of the IT department, articulating and implementing new policies that address the transition requires input from multiple departments such as legal, compliance, and risk. After articulating these policies and guidelines, the organizational expectations crystalized in them are propagated effectively. For instance, several organizations in our dataset used mandatory periodic training for educating their employees regarding these policies and the expectations they entail. 
5) One size does not fit all: The consumerization of IT has empowered workers to enact a complex, personalized infrastructure that combines privately-owned with organization-provided technology based on individual situations and preferences (Ortbach, Bode, \& Niehaves, 2013). Therefore, a pragmatic approach to the management of emerging IT infrastructure has to attend to and support the process of IT individualization, catering to the needs and preferences of different groups of employees. Organizations will either need to provide the multi-faceted and technological environments younger workers need or risk making the organization and its sphere of control irrelevant when digital natives make decisions to adopt IT. Organizations can effectively take advantage of potential benefits derived from the interplay between ubiquitous technological solutions and the passion of the new generation to adopt them (e.g., technological expertise of digital natives) by aligning their practices, strategies, and technology polices with the different expectations, motivations, and workstyles of all generations of workers. In doing so, organizations should strive to understand how workers perform their work and use technology for that purpose-individually, generationally, and within their roles-and offer a wide range of options to accommodate a diverse range of workstyles (Salkowitz, 2008).

By focusing on different user segments, organizations will be able to balance their IT management approach between inflexible, one-size-fit-all strategies and individualization solutions such as bringyour-own-device (BYOD) or choose-your-own-device (CYOD).

By formulating and building on such approaches, the organization will be able to appreciate the unique characteristics of different groups of workers such as a natural tendency to be connected and technophilia. These groups can also contribute to "supporting infrastructure" that must be in place if organizations wish to take advantage of new technologies and their affordances (Kling \& Lamb, 1999). A crucial aspect of the supporting infrastructure, particularly when it comes to the generational issues, is "starting a dialogue about technology across the generations" (Salkowitz, 2008, p. 12) . Rather than merely promoting best-practices (which may only reflect the managers' preferences), facilitating communication among disparate organizational actors allows for effective exchanging of impressions and of experience with the new technology.

6) Creating a hospitable environment: To facilitate transitions, we observed that some organizations have created a hospitable social environment for the generation entering the workforce. This environment is created based on a recognition of the unique social characters of these workers such as a natural tendency to be connected, socialize, span boundaries, and experiment with new technologies (boyd, 2014; Elias, Smith, \& Barney, 2012; Oblinger, 2003; Vodanovich et al., 2010). Digital natives' embrace of social and collaborative technologies is not just driven by their enthusiasm 
for the latest gadget, but also reflects their generational approach to problem solving, social interaction and knowledge sharing (Salkowitz, 2008).

If younger workers don't find their personal preference addressed by their organization, and the organization misses an opportunity to empower them to connect and collaborate with one another, digital natives may pursue their passion for digitally-enabled social networks somewhere else, depriving the organization of the great potential offered by fresh ideas gleaned through social and informal ties. In this regard, one of the mangers in our sample notes: "I am absolutely convinced that if companies make use of those features like Facebook, they will gain a competitive advantage and if they don't do it at some point in time, they will actually lose people and they will lose the chance to realize on ideas that are in their company but they are not being found."

Many organizations have begun to leverage social technologies as strategic tools for human resource management (e.g., talent acquisition and campus outreach). Organizations now increasingly invoke social channels to attract new talent and to retain current employees (Michael Harvey et al., 2014; Singh \& Sharma, 2014). Contributing to another strategic goal of organizations, social technologies are also regarded as viable venues for fostering knowledge sharing activities and collaboration among employees (Gibbs, Rozaidi, \& Eisenberg, 2013; Jarrahi \& Sawyer, 2013).

Even if extensive considerations lead to a decision to oppose certain work practices or ban a technology, managers need to convey their decisions in a respectful manner such that it does not alienate any segment of the workforce. After all, today's organizations are likened to a fishbowl. Firms that constrain their employees too aggressively will quickly gain a repressive reputation, making them less capable of hiring and retaining top talents (Fleming \& Marx, 2006). Several companies included in our study had provided employees with the freedom to manage their work and time. These firms implicitly recognized the fact that employees feel socially fulfilled when they can make relationships and foster them through social technologies. In such a workplace, workers are responsible for certain deliverables, and should remain adequately productive; however, they are allowed to use their time in whatever ways they wish, including socializing with colleagues or surfing the social Web. One manager reflected on this approach: "If they want to spend their time on a social networking site, that's absolutely fine. The actual tasks remain to be done, whether they want to do those from 3 to 5 am and spend their more productive time elsewhere."

We also noted that many corporate policies discourage people from engaging in inter-organizational virtual communities enabled by public social media. This often leads to a "one-directional outside-in knowledge sharing strategy" whereby organizational members function primarily as consumers of information (Jarrahi \& Sawyer, 2015). Since these communities build on norms of reciprocity (Chang \& Chuang, 2011), this strategy may prove counterproductive or opportunistic. In this light, 
organizations' policies and performance review practices should consider, appreciate, and encourage the employees' active engagement in external communities. Presently, in most of the consulting firms we studied, employees are only rewarded based on their contribution to intra-organizational communities of practice that can also serve as a ground for professional development.

7) Taking advantage of personal social networks: The organizations adopting a pragmatic approach in our sample seem to have contemplated how they could invoke the fundamentals of social networking for fostering collaboration, innovation and sharing. The first step in this process is to appreciate, trust, and leverage employees' interpersonal connections for gaining competitive advantage by focusing on their aptitude for acquiring innovative knowledge. Past studies suggest that organizations whose employees are members of inter-organizational social networks will learn more efficiently and quickly (e.g., Hargadon \& Sutton, 1997; Yang \& Maxwell, 2011). Although these social ties (e.g., those that form communities of practice) are typically generated and nourished outside of the organization's sphere of influence, many organizations have begun employing strategies to encourage the inflow of information from social networks and they recognize the indirect benefits of social platforms that generate value in the long-term. We observed that some managers acknowledge the affordance of online social venues for importing relevant knowledge. A manger states: "If somebody needs to make a discussion in a certain forum, to get some ideas I do not care. If he goes to the library and then reads all the books or goes to a forum and discuss this with 10,000 people over the planet how to solve something, I don't see that is really a problem. I care if he shares secrets from the business model with others."

Weak ties in particular are considered a unique conduit of innovative knowledge (Hansen, 1999). Whether or not organizations endorse it, it is very common for many knowledge workers to reach out to their weak and strong ties outside the organizations for both personal and work-related purposes (Tortoriello \& Krackhardt, 2010). In many instances, social media are deemed useful for nurturing ties, and facilitating the transfer of innovative knowledge. A recent study of Twitter use suggests that Twitter users (particularly those with a diverse network) tend to have access to and generate more innovative ideas for the enterprise than non-users (Parise, Whelan, \& Todd, 2015). One of our informants explains further this affordance of Twitter: "Sometimes during the day at work, you are busy with your work and project, but you need time to sit back and envision and focus on where you want to grow as a person and as an employee. I use my external channels to get that type of information. The social tools offer the ability to have this global perspective when you talk to different people from different countries, different cultural backgrounds. You get a whole different view of the world. You can just be sitting in your chair and all these other ideas come to you that you never imagined sometimes." 
Managers can galvanize the inflow of knowledge and innovation by encouraging knowledge workers to cross-organizational boundaries using their social ties. We observed several pragmatic uses of social media for sharing across boundaries. For example, a consulting firm now uses consultants' Linkedln profiles as a means for locating expertise and communicating with customers. Previously consultants were expected to maintain a biography in the form of a MS Word document on a central resource management system, and update it right after each project. When a consultant is assigned to a project, the Linkedln profile is sent out to the customer and the customer can look at the consultant's areas of expertise, as well as professional and educational backgrounds. One of the most salient aspects of consultant work lies in extensive interactions with clients. Social networking platforms and collaborative systems are more beneficial if they enable consultants to embrace these interactions on some level. None of the enterprise social networking systems we studied in this research addressed this need and they were all only useful within the bounds of the consulting firm. In this light, the use of Linkedln as a publicly available social media allows the knowledge workers to interact and connect with client organizations in a more effective way. Furthermore, this use of Linkedln also lets the employees find and connect with interesting colleagues in this global firm.

\section{CONCLUSION}

In summary, the triad highlights the interrelationships among the three components, helping managers understand simultaneous and entwined changes in technological landscape, work practices and the composition and attitude of people entering the workforce. Consideration of these interrelationships provides useful direction for manager seeking to balance these components as they manage new technologies.

\section{REFERENCES}

Abdinnour-Helm, S., Lengnick-Hall, M. L., \& Lengnick-Hall, C. A. (2003). Pre-implementation attitudes and organizational readiness for implementing an enterprise resource planning system. European journal of operational research, 146(2), 258-273.

Avgerou, C. (2000). IT and organizational change: an institutionalist perspective. Information Technology \& People, 13(4), 234-262.

Boulton, C. (2007). Digital Natives Will Drive Web 2.0 into Your Business. Retrieved 15 Jan, 2016 from http://www.eweek.com/c/a/Messaging-and-Collaboration/Digital-Natives-Will-Drive-Web20-into-Your-Business

boyd, D. (2014). It's complicated: The social lives of networked teens. New Haven, CT: Yale University Press.

Brown, J. S., \& Duguid, P. (2000). Balancing act: Capturing knowledge without killing it. Harvard Business Review, 78(3), 73-80.

Carr, N. G. (2003). IT doesn't matter. Harvard Business Review, 81(5), 41-49.

Carter, M., Thatcher, J. B., Applefield, C., \& Mcalpine, J. (2011). What cell phones mean in young people's daily lives and social interactions. Paper presented at the Southern Association for Information Systems 2011 Proceedings. Paper, Atlanta, GA. 
Castro-Leon, E. (2014). Consumerization in the IT Service Ecosystem. IT Professional, 16(5), 20-27.

Chang, H. H., \& Chuang, S.-S. (2011). Social capital and individual motivations on knowledge sharing: Participant involvement as a moderator. Information \& Management, 48(1), 9-18.

Costello, T., \& Prohaska, B. (2013). 2013 Trends and Strategies. IT Professional(1), 64.

D'Arcy, P. (2011). ClO strategies for consumerization: The future of enterprise mobile computing. Dell ClO Insight Series. Dell Inc., 1-15.

Davenport, T. H. (1995). Process innovation: reengineering work through information technology: Harvard Business Press.

Davis, G. (2002). Anytime/anyplace computing and the future of knowledge work. Communications of the ACM, 45(12), 67-73.

Efimova, L., \& Grudin, J. (2008). Crossing boundaries: Digital literacy in enterprises. In C. Lankshear \& M. Knobel (Eds.), Digital Literacies: Concepts, policies, practices. New York: Peter Lang.

Elias, S. M., Smith, W. L., \& Barney, C. E. (2012). Age as a moderator of attitude towards technology in the workplace: work motivation and overall job satisfaction. Behaviour \& Information Technology, 31(5), 453-467.

Erickson, I., Jarrahi, M. H., Thomson, L., \& Sawyer, S. (2014). More than nomads: Mobility, knowledge work, and infrastructure. Paper presented at the the European Group for Organizational Studies Colloquium, Rotterdam, The Netherlands.

Finn, D., \& Donovan, A. (2013). PwC's NextGen: A Global Generational Study. Evoloving talent strategy to match the new worforce reality. Retrieved 20 Jan, 2016 from http://www.pwc.com/gx/en/hr-management-services/publications/assets/pwc-nextgen.pdf

Fister, J. (2010). Play to Your Workforce's Strengths; Interview with Jim Fister. MIT Sloan Management Review.

Fleming, L., \& Marx, M. (2006). Managing creativity in small worlds. California Management Review, 48(4), 6.

French, A. M., Guo, C., \& Shim, J. (2014). Current Status, Issues, and Future of Bring Your Own Device (BYOD). Communications of the Association for Information Systems, 35(1), 191-197.

Gaudin, S. (2012). Enterprises opening up to social networking. Retrieved 15 October, 2014 from http://www.computerworld.com/article/2502053/social-business/enterprises-opening-upto-social-networking.html

Gibbs, J. L., Rozaidi, N. A., \& Eisenberg, J. (2013). Overcoming the "ideology of openness": Probing the affordances of social media for organizational knowledge sharing. Journal of ComputerMediated Communication, 19(1), 102-120.

Györy, A., Cleven, A., Uebernickel, F., \& Brenner, W. (2012). Exploring the Shadows: IT Governance Approaches to User-Driven Innovation. Paper presented at the ECIS.

Hagel III, J., \& Brown, J. S. (2011). From push to pull: Emerging models for mobilizing resources. Journal of Service Science (JSS), 1(1), 93-110.

Hamel, G. (2009). Moon shots for management. Harvard Business Review, 87(2), 91-98.

Hansen, M. T. (1999). The search-transfer problem: The role of weak ties in sharing knowledge across organization subunits. Administrative science quarterly, 44(1), 82-85.

Hargadon, A., \& Sutton, R. I. (1997). Technology brokering and innovation in a product development firm. Administrative science quarterly, 42(4), 716-749.

Harris, J., Ives, B., \& Junglas, I. (2012). IT consumerization: when gadgets turn into enterprise IT tools. MIS Quarterly Executive, 11(3), 99-112.

Howe, N., \& Strauss, W. (2009). Millennials Rising: The Next Great Generation. New York: Vintage.

Hyman, J., \& Summers, J. (2004). Lacking balance?: Work-life employment practices in the modern economy. Personnel Review, 33(4), 418-429.

Jarrahi, M. H., \& Sawyer, S. (2013). Social technologies, informal knowledge practices, and the enterprise. Journal of Organizational Computing and Electronic Commerce, 23(1-2), 110-137. 
Jarrahi, M. H., \& Sawyer, S. (2015). Theorizing on the take-up of social technologies, organizational policies and norms, and consultants' knowledge-sharing practices. Journal of the Association for Information Science and Technology, 66(1), 162-179.

Kaplan, M. (2012). Banned on Wall St.: Facebook, Twitter and Gmail. The New York Times, Nov 22, 2012.

Kling, R., \& Lamb, R. (1999). IT and organizational change in digital economies: a socio-technical approach. ACM SIGCAS Computers and Society, 29(3), 17-25.

Kluth, A. (2008). Nomads at Last - A Special Report on Mobile Telecoms. The Economist, April 12th.

Leclercq-Vandelannoitte, A. (2015a). Leaving employees to their own devices: new practices in the workplace. Journal of Business Strategy, 36(5), 18-24.

Leclercq-Vandelannoitte, A. (2015b). Managing BYOD: how do organizations incorporate user-driven IT innovations? Information Technology \& People, 28(1), 2-33.

Malhotra, N., Morris, T., \& Hinings, C. R. B. (2006). Variation in organizational form among professional service organizations. Research in the Sociology of Organizations, 24, 171-202.

Malone, T., \& Laubacher, R. (1998). The dawn of the e-lance economy. Harvard Business Review, September-October.

Mazmanian, M., Orlikowski, W. J., \& Yates, J. (2013). The autonomy paradox: The implications of mobile email devices for knowledge professionals. Organization Science, 24(5), 1337-1357.

McAfee, A. (2009). Enterprise 2.0, New Collaborative Tools for Your Organization's Toughest Challenges. Boston, MA: Harvard Business School.

McGrane, K. (2013). The Rise of the Mobile-Only User. . Harvard Business Review HBR Blog Network. http://blogs.hbr.org/2013/05/the-rise-of-the-mobile-only-us/, March.

McKeen, J. D., Smith, H. A., \& Jin, J. Y. (2009). Developments in practice XXXII: Successful strategies for IT staffing. Communications of the Association for Information Systems, 24(1), 805-820.

Michael Harvey, D., Timothy Kiessling, D., Fisher, R., McPhail, R., You, E., \& Ash, M. (2014). Using social media to recruit global supply chain managers. International Journal of Physical Distribution \& Logistics Management, 44(8/9), 635-645.

Miller, K. W., Voas, J., \& Hurlburt, G. F. (2012). BYOD: Security and privacy considerations. IT Professional(5), 53-55.

Morrow, B. (2012). BYOD security challenges: control and protect your most sensitive data. Network Security, 2012(12), 5-8.

Newkirk, H. E., \& Lederer, A. L. (2006). The effectiveness of strategic information systems planning under environmental uncertainty. Information \& Management, 43(4), 481-501.

Niehaves, B., Köffer, S., \& Ortbach, K. (2012). IT Consumerization - A Theory and Practice Review. Paper presented at the AMCIS 2012 Seattle, Washington

Nohria, N. (1998). Is a network perspective a useful way of studying organizations. In N. Nohria \& R. Eccles (Eds.), Leading organizations: Perspectives for a new era (pp. 287-301). Boston: Harvard Business School Press.

Oblinger, D. (2003). Boomers Gen-Xers Millennials. EDUCAUSE review, 500(4), 37-47.

Oblinger, D., \& Oblinger, J. L. (2005). Educating the Net Generation. Boulder, CO: EDUCAUSE Publishers.

Orlikowski, W. (2000). Using technology and constituting structures: A practice lens for studying technology in organizations. Organization Science, 11(4), 404-428.

Orlikowski, W. J., \& Barley, S. (2001). Technology and institutions: What can research on information technology and research on organizations learn from each other? MIS quarterly, 25(2), 145165.

Ortbach, K., Bode, M., \& Niehaves, B. (2013). What influences technological individualization?-an analysis of antecedents to IT consumerization behavior. Paper presented at the AMCIS 2013, Chicago, IL.

Parise, S., Whelan, E., \& Todd, S. (2015). How Twitter Users Can Generate Better Ideas. MIT Sloan Management Review, 56(4), 21. 
Romer, H. (2014). Best practices for BYOD security. Computer Fraud \& Security, 2014(1), 13-15.

Sadler, K., Robertson, T., Kan, M., \& Hagen, P. (2006). Balancing work, life and other concerns: a study of mobile technology use by Australian freelancers. Paper presented at the NordiCHI.

Salkowitz, R. (2008). Generation blend: Managing across the technology age gap. New Jersey: John Wiley \& Sons.

Shelton, T. (2013). Business Models for the Social Mobile Cloud: Transform Your Business Using Social Media, Mobile Internet, and Cloud Computing. New Jersey John Wiley \& Sons.

Singh, K., \& Sharma, S. (2014). Effective use of social media for talent acquisition and recruitment. International Journal of Intercultural Information Management, 4(4), 228-237.

Swanson, E. B., \& Ramiller, N. C. (2004). Innovating Mindfully with Information Technology. MIS quarterly, 28(4), 553-583.

Tapscott, D. (2009). Grown up digital: McGraw-Hill New York.

Tilson, D., Lyytinen, K., \& Sørensen, C. (2010). Research commentary-digital infrastructures: the missing IS research agenda. Information Systems Research, 21(4), 748-759.

Tilvawala, K., Sundaram, D., \& Myers, M. D. (2013). Design of Organisational Ubiquitous Information Systems: Digital Native and Digital Immigrant Perspectives. Paper presented at the Pacific Asia Conference on Information Systems, Jeju Island, Korea.

Tortoriello, M., \& Krackhardt, D. (2010). Activating cross-boundary knowledge: the role of Simmelian ties in the generation of innovations. Academy of Management Journal, 53(1), 167-181.

Valdes, M., \& Mcfarland, S. (2012). Job seekers getting asked for Facebook passwords. Associated Press, Mar 20.

Vodanovich, S., Sundaram, D., \& Myers, M. (2010). Research commentary-Digital natives and ubiquitous information systems. Information Systems Research, 21(4), 711-723.

Wang, Q. E., Myers, M. D., \& Sundaram, D. (2013). Digital natives and digital immigrants. Business \& Information Systems Engineering, 5(6), 409-419.

Warmer, R. (2013). Who Wastes More Time at Work: Millennials, Gen X'ers or Boomers? Retrieved $10 \mathrm{Feb}, 2016$ from http://www.huffingtonpost.com/russ-warner/who-wastes-more-time-atw b 2618279.html

Weeger, A., Wang, X. A., Gewald, H., Sanchez, O. P., Raisinghani, M., Grant, G., \& Pittayachawan, S. (2015). Determinants of Intention to Participate in Corporate BYOD-Programs-The Case of Digital Natives-. Paper presented at the Academy of Management Proceedings.

Winter, S., Berente, N., Howison, J., \& Butler, B. (2014). Beyond the organizational 'container': Conceptualizing 21st century sociotechnical work. Information and Organization, 24(4), 250269.

Yang, T.-M., \& Maxwell, T. A. (2011). Information-sharing in public organizations: A literature review of interpersonal, intra-organizational and inter-organizational success factors. Government Information Quarterly, 28(2), 164-175.

Zammuto, R. F., Griffith, T. L., Majchrzak, A., Dougherty, D. J., \& Faraj, S. (2007). Information technology and the changing fabric of organization. Organization Science, 18(5), 749-762. 